\title{
Multiple actuations of salbutamol MDI into a spacer device reduce the amount of drug recovered in the respirable range
}

\author{
P.W. Barry, C. O'Callaghan
}

\begin{abstract}
Multiple actuations of salbutamol MDI into a spacer device reduce the amount of drug recovered in the respirable range. P.W. Barry. C. O'Callaghan. CERS Journals Ltd 1994.

ABSTRACT: We wanted to determine the amount of salbutamol available in respirable particles from the Volumatic spacer device after one, two or five actuations of a metered-dose inhaler into the spacer prior to analysis.

A glass multistage liquid impinger was used to determine particle size. Aerosol was sampled after one, two or five actuations from a metered-dose inhaler into a Volumatic spacer. Each experiment was repeated four times.

The amount of salbutamol recovered per actuation in particles less than $5 \mu \mathrm{m}$ (mean and 95\% confidence intervals) was: $54.3 \mu \mathrm{g}$ (48.3-60.1) after one actuation; 42.4 $\mu \mathrm{g}$ (38.2-46.5) after two actuations, and $20.7 \mu \mathrm{g}(17.5-23.9)$ after five actuations.

We conclude that multiple actuations of salbutamol into the Volumatico spacer do not linearly increase the amount of drug available for inhalation. To maximize drug delivery, single actuations should be used prior to inhalation. In comparative studies of drugs and dosages, it must be remembered that the amount of drug delivered is not the same as that administered.

Eur Respir J., 1994, 7, 1707-1709.
\end{abstract}

In the delivery of drugs to the respiratory tract, spacer devices are used to reduce the need to co-ordinate inhalation and metered-dose inhaler (MDI) actuation. Optimum spacer use improves asthma management and reduces the waste of drugs, which result from poor inhaler technique [1].

Factors which affect the amount of drug obtained from spacers are not widely appreciated. Recent guidelines for the management of acute severe asthma recommend the administration of multiple doses of bronchodilator to the patient when a nebuliser is not available [2]. Another recently published study used multiple doses of salbutamol administered via a spacer to determine dose equivalence of salbutamol and salmeterol [3]. We hypothesized that the calculated dose of salbutamol administered in this way would not be the same as the dose delivered to the patient, compromising treatment and invalidating dose equivalence calculations.

The study therefore determined the effect of multple actuations of salbutamol $100 \mu \mathrm{g} \cdot$ actuation into a Volumatic 1 spacer on the amount of drug present in particles within the respirable range.

\section{Methods}

A glass multistage liquid impinger (MSLI), as modified by BELL et al [4] was used to determine the MDI output under different conditions. The MSLI operates
Dept of Child Health, University of Leicester, Leicester, UK.

Correspondence: C. O'Callaghan

Dept of Child Health

University of Leicester

Clinical Sciences Building

Leicester Royal Infirmary

PO Box 65

Leicester LE2 7LX

UK

Keywords: Asthma drug administration drug delivery devices salbutamol

Received: January 121994

Accepted for publication June 181994 by drawing an aerosol through a series of stages, each containing a glass impaction plate. Aerosol velocity increases in the device and progressively smaller particles collect at each stage. A filter after the final stage collects the smallest particles. Each stage was washed with methanol, and the amount of drug collected in each stage was assayed by high performance liquid chromatography with an ultra-violet detector at a wavelength of $276 \mathrm{~nm}$.

A standard MDI of salbutamol (Allen \& Hanburys, $100 \mu \mathrm{g}$ per actuation) was shaken for $10 \mathrm{~s}$, connected to the MSLI and discharged into it. This was repeated 10 times to facilitate the drug assay.

The experiment was repeated using the Volumatic spacer. The MDI was shaken and then actuated into the spacer. This was immediately attached to the MSLI. The spacer was positioned so that drug would not be drawn into the MSLI before attachment. To assess the effect of multiple actuations into the spacer, the MDI was actuated into the spacer one, two or five times prior to attaching it to the MSLI. For each of the experiments, the aerosol was actuated a total of 10 times. Before each actuation, the MDI was shaken for $10 \mathrm{~s}$. Five new metered-dose inhalers were used. The first 10 doses from each were discarded, and the metered dose-inhaler primed by firing one shot to waste prior to each experiment.

Each experiment was repeated four times, and the temperature, relative humidity and barometric pressure were recorded. The size distribution of the aerosol cloud was 
Table 1. - The effect of different methods of use of the Volumatico on the delivery of salbutamol

\begin{tabular}{|c|c|c|c|c|c|}
\hline \multirow[t]{2}{*}{ Method of delivery } & \multicolumn{3}{|c|}{ Salbutamol recovered $(\mu \mathrm{g})$ per $100 \mu \mathrm{g}$ actuation } & \multirow[b]{2}{*}{$\underset{\mu \mathrm{m}}{\mathrm{MMAD}}$} & \multirow[b]{2}{*}{ GSD } \\
\hline & $\begin{array}{l}\text { Dose to } \\
\text { patient }\end{array}$ & $\begin{array}{l}\text { In particles } \\
<5 \mu \mathrm{m}\end{array}$ & $\begin{array}{l}\text { In particles } \\
<3 \mu \mathrm{m}\end{array}$ & & \\
\hline $\begin{array}{l}\text { Direct from metered- } \\
\text { dose inhalers }\end{array}$ & $\begin{array}{c}90.5 \\
(81.4-99.6)\end{array}$ & $\begin{array}{c}46.3 \\
(36.3-56.3)\end{array}$ & $\begin{array}{c}34.4 \\
(27.5-41.3)\end{array}$ & - & - \\
\hline \multicolumn{6}{|c|}{ Via Volumatic@spacer: } \\
\hline 1 actuation & $\begin{array}{c}62.1 \\
(56.0-68.2)\end{array}$ & $\begin{array}{c}54.3 \\
(48.3-60.1)\end{array}$ & $\begin{array}{c}44.9 \\
(39.0-50.8)\end{array}$ & $\begin{array}{c}1.74 \\
(1.57-1.90)\end{array}$ & $\begin{array}{c}2.41 \\
(2.30-2.51)\end{array}$ \\
\hline 2 actuations & $\begin{array}{c}49.7 \\
(45.9-53.4)\end{array}$ & $\begin{array}{c}42.4 \\
(38.2-46.5)\end{array}$ & $\begin{array}{c}34.9 \\
(31.1-38.8)\end{array}$ & $\begin{array}{c}1.75 \\
(1.21-2.30)\end{array}$ & $\begin{array}{c}2.92 \\
(1.98-3.85)\end{array}$ \\
\hline 3 actuations & $\begin{array}{c}22.7 \\
(18.7-26.7)\end{array}$ & $\begin{array}{c}20.7 \\
(17.5-23.9)\end{array}$ & $\begin{array}{c}17.5 \\
(14.9-20.1)\end{array}$ & $\begin{array}{c}1.61 \\
(1.47-1.75)\end{array}$ & $\begin{array}{c}2.27 \\
(2.09-2.45)\end{array}$ \\
\hline
\end{tabular}

Data are presented as mean and 95\% confidence interval in parenthesis, MMAD: mass median aerodynamic diameter; GSD: geometric standard deviation.

determined from the amount of drug recovered from each stage; the MSLI having been previously calibrated with an aerosol of known particle size distribution operating under the same conditions as in this experiment.

\section{Results}

Particles smaller than 5 um are thought to enter the respiratory tract (the respirable range). We report on the amount of drug contained in particles smaller than 5 and $3 \mu \mathrm{m}$, the mass median aerodynamic diameter (MMAD) and the geometric standard deviation (GSD) [5] for each experiment. The amount of drug recovered (mean and 95\% confidence intervals), the MMAD and GSD for the different experiments are given in table 1.

Mean temperature was $23.1^{\circ} \mathrm{C}$ (range $21-25^{\circ} \mathrm{C}$ ), mean barometric pressure was $1005 \mathrm{mmHg}$ (range 998-1014 $\mathrm{mmHg}$ ) and the mean relative humidity was $56 \%$ (range $47-65 \%)$.

Use of the Volumatic 1 spacer increased the amount of salbutamol available for inhalation by 17 and $30 \%$ in particles less than 5 and $3 \mu \mathrm{m}$, respectively. Multiple actuations decreased drug recovery per $100 \mu \mathrm{g}$ actuation by $22 \%$ ( 2 actuations) and $62 \%$ ( 5 actuations) for particles less than $5 \mu \mathrm{g}$ compared with single actuations. Thus, when five $100 \mu \mathrm{g}$ actuations were released into the spacer before inhalation, only $103 \mu \mathrm{m}$ were recovered in particles smaller than $5 \mu \mathrm{m}$. If the same number of actuations had been administered with an inhalation between each one, $270 \mu \mathrm{g}$ would have been recovered.

\section{Discussion}

Multiple actuations of salbutamol $100 \mu \mathrm{g} \cdot$ actuation $^{-1}$ into the Volumatic $\$$ spacer decrease the amount of drug present in particles within the respirable range. In these circumstances, dose delivered is not the same as dose administered. This is important where the dose deliv- ered needs to be high, as in the treatment of an exacerbation of asthma, and where the dose delivered needs to be precisely known, for instance in comparative studies of the effects of different drugs.

Current British Thoracic Society guidelines suggest the administration of two puffs of bronchodilator into a spacer device prior to inhalation in the emergency treatment of asthma in adults, where a nebulizer is not available [2]. Administering each puff separately would increase the amount of drug available for inhalation by over $20 \%$. Previous guidelines recommended inhalation after multiples of five puffs, reducing respirable drug delivery by almost two thirds [6].

If spacers are used in studies of dosimetry, conclusions on dose-equivalence and dose response may be made from an incorrect assumption of dose delivered. In a recent study, the dose equivalence of salmeterol and salbutamol in patients with asthma was determined [3]. Salbutamol was delivered by multiples of five actuations into a Volumatico spacer prior to inhalation, and salmeterol by metered-dose inhaler without a spacer. It was estimated that $50 \mu \mathrm{g}$ of salmeterol was equivalent to up to $500 \mu \mathrm{g}$ of salbutamol. Our study suggests that administering $500 \mu \mathrm{g}$ of salbutamol in the way described delivers only the same amount of respirable drug as two separate $100 \mu \mathrm{g}$ actuations.

The present study confirms our earlier work and that of others into multiple dosing into spacer devices with sodium cromoglycate $[5,7,8]$, and nedocromil sodium [9]. Multiple actuations of the MDI may decrease the amount of respirable drug recovered because of agglomeration of particles increasing their size, displacement of aerosol out of the spacer or onto the spacer walls, or the electrostatic attraction of particles to the spacer and each other. As different drug formulations and spacer devices have different physical and electrostatic properties, findings of one study may not be applicable to other drugs and devices.

For the administration of salbutamol use of the Volumatic spacer device increases the amount of drug available for inhalation in respirable particles provided that multiple actuations into the Volumatic $₫$ are avoided. 


\section{References}

1. Keeley D. Large volume plastic spacers in asthma (Editorial). Brit Med J 1992; 305: 598-599.

2. British Thoracic Society. Guidelines for the management of asthma. Thorax 1993; 48: S1-S24.

3. Smyth ET, Pavord ID, Wong CS, Wisniewski AFZ, Williams J, Tattersfield AE. Interaction and dose equivalence of salbutamol and salmeterol in patients with asthma. Br Med J 1993; 306: 543-545.

4. Bell JH, Brown K, Glasby J. Variations in the delivery of isoprenaline from various pressurised inhalers. J Pharm Pharmacol 1973; 25 (Suppl.): 32-36.

5. O'Callaghan C, Lynch J, Cant M, Robertson C. Improvement in drug delivery from spacer devices by use of an antistatic lining. Thorax 1993; 48: 603-606.

6. British Thoracic Society. Guidelines for the management of asthma in adults. II. Acute severe asthma. $\mathrm{Br}$ Med J 1990; 301: 797-800.

7. Everard ML, Clark AR, Milner AD. Drug delivery from holding chambers with attached facemask. Arch Dis Child 1992; 67: 580-585.

8. Clark AR, Rachelefsky G, Mason PL, Goldenhersh MJ, Hollingworth A. The use of reservoir devices for the simultaneous delivery of two metered dose aerosols. Allergy Clin Immunol 1990; 85: 75-79.

9. Barry PW, Robertson C, O'Callaghan C. Effects of different methods of use of a spacer on the delivery of nedocromil sodium. Arch Dis Child 1993; 69: 693-694. 